\title{
Mother's depression at childbirth does not contribute to the effects of antenatal depression on neonate's behavioral development
}

\author{
Alexandra Pacheco ${ }^{\mathrm{a}, \mathrm{b}, *}$, Bárbara Figueiredo $^{\mathrm{b}}$ \\ a Center for Childhood and Youth District, Social Security Centre of Oporto, Portugal \\ b School of Psychology, Minho University, Portugal
}

\section{A R T I C L E I N F O}

\section{Article history:}

Received 22 February 2011

Received in revised form

13 November 2011

Accepted 28 February 2012

\section{Keywords:}

Childbirth

Depression

Face/voice preference

Habituation

Neonate

pregnancy

\begin{abstract}
A B S T R A C T
Background: Maternal depression is a worldwide phenomenon that has been linked to adverse developmental outcomes in neonates.

Aims: To study the effect of antenatal depression (during the third trimester of pregnancy) on neonate behavior, preference, and habituation to both the mother and a stranger's face/voice. To analyze mother's depression at childbirth as a potential mediator or moderator of the relationship between antenatal depression and neonate behavioral development. Method: A sample of 110 pregnant women was divided in 2 groups according to their scores on the Edinburgh Postnatal Depression Scale during pregnancy (EPDS; $\geq 10$, depressed; $<10$, non-depressed). In the first 5 days after birth, neonatal performance on the Neonatal Behavioral Assessment Scale (NBAS) and in the 'Preference and habituation to the mother's face/voice versus stranger' paradigm was assessed; each mother filled out an EPDS.

Results: Neonates of depressed pregnant women, achieved lower scores on the NBASs (regulation of state, range of state, and habituation); did not show a visual/auditory preference for the mother's face/voice; required more trials to become habituated to the mother's face/voice; and showed a higher visual/auditory preference for the stranger's face/voice after habituation compared to neonates of non-depressed pregnant women. Depression at childbirth does not contribute to the effect of antenatal depression on neonatal behavioral development.

Conclusion: Depression even before childbirth compromises the neonatal behavioral development. Depression is a relevant issue and should be addressed as a routine part of prenatal health care.
\end{abstract}

(c) 2012 Elsevier Inc. All rights reserved.

In a previous study, Figueiredo, Pacheco, Costa, Conde, and Teixeira (2010) found that neonates of depressed and/or anxious mothers compared to newborns of non-anxious/non-depressed mothers presented worse behavioral development, namely, they did not show a visual/auditory preference for their mother's face/voice nor improved preference for those of a stranger after habituation to their mother's face/voice. Part of this study is a replication of the data of Figueiredo et al. (2010); nevertheless, we included a more complete assessment of neonate behavioral development, with the administration of the Neonatal Behavioral Assessment Scale (NBAS). Our purpose is to study if the results obtained can also be observed in other dimensions of neonatal development. This study uses a different sample and a different statistical procedure to test if depression at birth is a mediator/moderator of the relationship between antenatal depression and neonatal neurobehavior. Another innovation is the focus on depressive symptomatology instead of depression and anxiety simultaneously.

\footnotetext{
* Corresponding author at: School of Psychology, Minho University, Campus de Gualtar, 4710-056 Braga, Portugal. Tel.: +351 253 604241; fax: +351 253 678987.

E-mail address: alexandrap@psi.uminho.pt (A. Pacheco).
} 
Antenatal and postpartum maternal depression is a worldwide phenomenon (Dieter, Emory, Johnson, \& Raynor, 2008) affecting 10-25\% of women (Andersson, Sundstrom-Poromaa, Wulff, Astrom, \& Bixo, 2004; Marcus, Flynn, Blow, \& Barry, 2003; Teixeira, Figueiredo, Conde, Pacheco, \& Costa, 2009). A prevalence of $15.5 \%$ was found at early and mid-pregnancy, $11.1 \%$ in the third trimester and $8.7 \%$ in the postpartum period (Felice, Saliba, Grech, \& Cox, 2004). In a recent study with a Portuguese sample, rates of depression in the first, second, and third trimesters were high: $22 \%, 20.6 \%$, and $18.5 \%$, respectively (Teixeira et al., 2009). In an earlier study, the postpartum rates were $12.4 \%$ in the first week and $13.7 \%$ at 3 months (Costa, Pacheco, \& Figueiredo, 2007).

Several authors have devoted their efforts to the study of the impact of maternal depressive symptoms on neonate development. Depressed pregnant women are more likely to deliver prematurely and have low birth weight infants (Dayan et al., 2006; Field et al., 2004). Depressed pregnant women's infants showed a profile of dysregulation in their behavior, physiology, and biochemistry (Field, 1998), presenting with higher cortisol and lower dopamine and serotonin levels than did infants of non-depressed mothers (Field et al., 2004; Lundy et al., 1999). Neurobehavioral dysregulation has been studied in neonates of depressed pregnant women using the Brazelton Neonatal Behavioral Assessment Scale (NBAS), with data revealing that neonates of depressed pregnant women showed poorer performance on the orientation cluster, more depressive behaviors, lessened motor tone (Abrams, Field, Scafidi, \& Prodromidis, 1995; Lundy, Field, \& Pickens, 1996), lower scores on orienting clusters, and scored less optimally on the cuddliness and hand-to-mouth activity items (Hernandez-Reif, Field, Diego, \& Ruddock, 2006) compared to neonates of non-depressed pregnant women. Difficulty in discriminating stimuli, including the lack of a preference for the voice/face of the mother versus that of the stranger and longer habituation periods were also reported in infants of depressed pregnant women (e.g. Figueiredo et al., 2010; Hernandez-Reif, Field, Diego, \& Largie, 2002). These studies underscore the possibility that prenatal depressive symptoms, through an intrinsic genetic predisposition and/or a chemically imbalanced prenatal environment, may affect both maternal and infant neuroregulation as well as infant performance on neurobehavioral measures (Marcus et al., 2011). Mechanisms that could explain this profile of dysregulation associated with depression during pregnancy include: higher levels of cortisol, norepinephrine, beta-endorphin, and corticotropin-releasing hormones (Field, 1998); a reduction in uterine blood flow though the placenta (Glover, 1997; O'Donnell, O'Connor, T. G., \& Glover, 2009); and inadequate prenatal care (e.g. poor maternal levels of nutrition; use of tobacco, alcohol, and drugs; and coffee consumption) (e.g. Romo, Carceller, \& Tobajas, 2009).

There is growing evidence that neonatal behavior combined with the caregiving environment predict child development outcomes. Following birth, the first contacts between the mother and the neonate benefit their emotional involvement (Klaus \& Kennell, 1976), promoting the identification of and response to the child's needs (maternal sensitivity), and guaranteeing the essential proximity necessary for the infant's survival (Bowlby, 1969). Nevertheless, this is a sensitive period for the mother since depressive mood may result from the abrupt drop in levels of circulating hormones (Payne, 2003). Postpartum blues involves a mild emotional disturbance appearing in the first week following childbirth, lasting from a few hours to 10 days. This condition has been reported to occur in $20-80 \%$ of new mothers, making it the most common and least severe postnatal depressive syndrome (O'Hara, Zekoski, Philipps, \& Wright, 1990). Usually associated with biological factors unique to the childbirth normative experience, no available evidence links postpartum blues to adverse effects on child development (Sohr-Preston \& Scaramella, 2006). However, Hernandez-Reif et al. (2002) showed that neonates whose mothers were depressed at birth failed to show an initial visual/auditory preference for their mothers' versus a female stranger's face/voice, required more trials and almost twice as long to habituate, and failed to show preference for a female stranger's face/voice after habituation. In addition, women who experience postpartum blues may be at increased risk for developing postpartum depression (Hannah, Adams, Lee, Glover, \& Sandler, 1992; Teissedre \& Chabrol, 2004). Postnatal depression is considered an early life stressor for the infant, in part because it is associated with lower levels of sensitive and responsive care essential for the development of healthy attachment relationships, emotional regulation skills, interpersonal skills, and stress response mechanisms (Lovejoy, Graczyk, O'Hare, \& Neuman, 2000).

Prospective studies have concluded that half of the women who were depressed during pregnancy remained depressed during the postpartum period (e.g. Gorman et al., 2004), postpartum depressed women were usually depressed during pregnancy (Da Costa et al., 2000; Figueiredo, Pacheco, Costa, \& Magarinho, 2007) and depression during pregnancy was the main risk factor for postpartum depression (e.g. Kitamura et al., 2006). Consequently, it is still not clear if the effects observed in neonates are the result of depression during pregnancy, postpartum, or both.

Children's exposure to chronic maternal depression seems to be associated with outcomes that are more problematic for children, perhaps because depression interferes with the mother's ability to respond sensitively and consistently over time. Diego, Field and Hernandez-Reif (2005) reported that neonatal behavior was influenced not just by the presence but also by the timing and duration of maternal depression symptoms. In their study: (1) neonates born to mothers reporting symptoms of depression during mid-pregnancy or postpartum (first 2 weeks after birth) exhibited greater periods of indeterminate sleep than did neonates of non-depressed mothers; (2) neonates born to mothers reporting prenatal depression spent more time fussing and crying, and exhibited more stress behaviors than neonates born to non-depressed mothers or neonates born to mothers exhibiting symptoms of depression only during the postpartum assessment; and (3) neonates born to mothers exhibiting symptoms of depression during both the prepartum and the postpartum assessments exhibited less optimal Brazelton neurobehavioral assessment scores than did neonates of non-depressed mothers or neonates born to mothers who exhibited symptoms of depression only during prepartum or postpartum assessments (Diego et al., 2005). Nevertheless, most studies of children with depressed parents have been cross-sectional, which does not allow for an examination of depression chronicity, course, or timing. This issue is particularly relevant (given the episodic and recurrent nature of depression) for the 
study of the mediator or moderator function that postpartum depression may have on the relationship between antenatal depression and infant development. On the other hand, as already reported above, the intervening or causal variables by which maternal depression affects infant development are conceptualized in a mediation process (Baron \& Kenny, 1986; Kraemer, Stice, Kazdin, Offord, \& Kupfer, 2001).

The current study analyzes the impact of the mother's depression on neonatal behavioral development. In particular, it was designed to study the effect of mother's depression during the third trimester, on neonatal behavior, preference and habituation to the mother's and stranger's face/voice. In addition, the mother's depression at birth was tested as a potential mediator/moderator of the relationship between antenatal depression and neonatal behavioral development.

\section{Methods}

\subsection{Participants}

A sample of pregnant women attending routine pre-natal care visits during the second trimester of gestation was prospectively recruited in two primary health care centers. All singletons, primigravida, low-risk pregnant women who were able to read, write and speak Portuguese were sequentially approached, and 88.6\% accepted to participate.

The sample was composed by 110 pregnant women. Two groups were formed attending the EPDS scores at the 3rd trimester of gestation (EPDS $\geq 10$ : depressed mother's group, $n=55$; vs. EPDS <10: non-depressed mother's group, $n=55$ ). Depressed an non-depressed groups were formed by a random stratification procedure to ensure group equivalence on mother's age ( $\leq 29 v s$. $>30$ years $)\left(\chi^{2}(1)=1.000, p=.642\right)$, years of schooling $\left(<9 v s\right.$. $\geq 9$ years of schooling) $\left(\chi^{2}(1)=1.000\right.$, $p=.642$ ), professional status (employed $v s$. unemployed) $\left(\chi^{2}(1)=1.000, p=.642\right.$ ) and matrimonial status (married or cohabiting vs. single) $\left(\chi^{2}(1)=1.000, p=.642\right)$. All mothers were Caucasian and primiparous and $93.4 \%$ were Portuguese (see Table 1 ). No differences between depressed and non-depressed mother's groups were present in terms of pregnancy and delivery medical data: time of gestation $\left(\chi^{2}(1)=0.610, p=.421\right)$, type of delivery $\left(\chi^{2}(1)=0.120, p=.087\right)$, anesthesia epidural $\left(\chi^{2}(1)=0.192\right.$, $p=.155)$, need to perform reanimation maneuvers to guarantee conditions for neonatal survival at birth $\left(\chi^{2}(1)=0.772\right.$, $p=.524)$, nor in terms of neonate characteristics: 1 st min apgar index $\left(\chi^{2}(1)=0.524, p=.478\right)$, weight $\left(\chi^{2}(1)=0.694, p=.527\right)$, length $\left(\chi^{2}(1)=0.825, p=.493\right)$, cephalic perimeter $\left(\chi^{2}(1)=1.000, p=.642\right)$, gender $\left(\chi^{2}(1)=0.701, p=.424\right)$ (see Table 1$)$. Significant associations were found between pregnant women's depression at the third pregnancy trimester and mother's depression at birth $\left(\chi^{2}=23.784, p=.000\right)$. More than half $(54.5 \%)$ of the depressed women in pregnancy were still depressed at birth, and the majority (89.1\%) of the non-depressed women in pregnancy remained non-depressed after childbirth.

\subsection{Measures}

Edinburgh Postnatal Depression Scale (EPDS; Cox, Holden, \& Sagovsky, 1987). The EPDS is a self-report questionnaire composed of 10 items in a likert scale of 4 points (0-3) to assess depression. EPDS Portuguese version showed good internal consistency (Cronbach's alpha $=0.85$ ) and test-retest reliability (Spearman Correlation $=0.75)$. A score equal or higher than 10 indicates the need to screen for a major depressive episode with a sensitivity of 65\% and specificity of 96\% (Areias, Kumar, Barros, \& Figueiredo, 1996).

Neonatal Behavioral Assessment Scale (NBAS; Brazelton \& Nugent, 1995). The NBAS assesses the newborn's competencies across different developmental areas - autonomic, motor, states and social - and describes how these areas are integrated. The scale, composed of 28 behavioral and 18 reflex items, is suitable for examining newborns and infants up to 2 months old. The 28 behavioral items are scored on a 9-point scale and the 18 reflex items on a 3-point scale. Behavioral and reflexes items were recorded so that a better performance corresponds to higher score and were then added in eight scales: habituation, orientation, motor, range of state, regulation of state, autonomic stability, excitability score, depressed score; and a total score. The Cronbach's alpha of the scales ranged from .54 (autonomic stability) to .74 (range of state) (Costa et al., 2010).

"Preference and habituation to the mother's face/voice versus stranger" paradigm (Hernandez-Reif et al., 2002; modified from Field, Cohen, Garcia, \& Greenberg, 1984). This procedure (see Figueiredo et al., 2010), occurred in the mother's hospital room, in 3 phases:

(1) Newborn's pretest visual/auditory preference. The dependent variables measured were the duration of the infant's looking (in seconds) at the mother's face (sum of seconds of looking in 2 trials), the duration of the infant's looking at the stranger's face (sum of seconds of looking in 2 trials) and the preference for the mother's face/voice (difference between the duration of the infant's looking at the mother and the stranger).

(2) Newborn's habituation: Habituation was recorded in a dichotomous variable: $0=$ better performance (4 or less trials to reach habituation response), 1 = worst performance (5-9 trials to reach habituation response).

(3) Newborn's posttest visual/auditory preference: The dependent variables measured were the duration of the infant's looking (in seconds) at the mother's face (sum of seconds of looking in 2 trials), at the stranger's face (sum of seconds of looking in 2 trials) and the preference for the stranger's face/voice (difference between the duration of the infant's looking at the stranger and the mother). 
Table 1

Pregnant women's socio-demographics, pregnancy and delivery medical data and neonatal characteristics.

\begin{tabular}{|c|c|c|c|}
\hline & Total $(N=110)(\%)$ & Depressed $(n=55)(\%)$ & Non-depressed $(n=55)(\%)$ \\
\hline \multicolumn{4}{|l|}{ Pregnant } \\
\hline \multicolumn{4}{|l|}{ Age (years) ${ }^{\mathrm{a}}$} \\
\hline$\leq 29$ & 69.2 & 34.6 & 34.6 \\
\hline$>30$ & 30.8 & 15.4 & 15.4 \\
\hline \multicolumn{4}{|l|}{ Years of schooling ${ }^{\mathrm{a}}$} \\
\hline$<9$ & 55.6 & 27.8 & 27.8 \\
\hline$\geq 9$ & 44.4 & 22.2 & 22.2 \\
\hline \multicolumn{4}{|l|}{ Professional status ${ }^{\mathrm{a}}$} \\
\hline Employed & 29.2 & 14.6 & 14.6 \\
\hline Unemployed & 70.8 & 35.4 & 35.4 \\
\hline \multicolumn{4}{|l|}{ Matrimonial status $^{\mathrm{a}}$} \\
\hline Married/cohabiting & 92.8 & 46.4 & 46.4 \\
\hline Single & 7.2 & 3.6 & 3.6 \\
\hline \multicolumn{4}{|l|}{ Pregnancy and delivery } \\
\hline \multicolumn{4}{|l|}{ Time of gestation } \\
\hline$<37$ & 11.2 & 6.1 & 5.1 \\
\hline$\geq 37$ & 88.8 & 43.9 & 44.9 \\
\hline \multicolumn{4}{|l|}{ Type of delivery } \\
\hline Eutocic & 51.8 & 22.1 & 29.7 \\
\hline Distocic & 48.2 & 27.9 & 20.3 \\
\hline \multicolumn{4}{|l|}{ Anesthesia epidural } \\
\hline No & 13.5 & 9 & 4.5 \\
\hline Yes & 86.5 & 41 & 45.5 \\
\hline \multicolumn{4}{|l|}{ Reanimation } \\
\hline No & 91.5 & 46.2 & 45.3 \\
\hline Yes & 8.5 & 3.8 & 4.7 \\
\hline \multicolumn{4}{|l|}{ Neonate } \\
\hline \multicolumn{4}{|l|}{ Apgar index: 1st min } \\
\hline$<7$ & 2.8 & 1.8 & 1.0 \\
\hline$\geq 7$ & 97.2 & 48.2 & 49 \\
\hline \multicolumn{4}{|l|}{ Weight (g) } \\
\hline$<2500$ & 4.8 & 3.4 & 1.4 \\
\hline$\geq 2500$ & 95.2 & 46.6 & 48.6 \\
\hline \multicolumn{4}{|l|}{ Length $(\mathrm{cm})$} \\
\hline$<48$ & 36.2 & 19.5 & 16.7 \\
\hline$\geq 48$ & 63.8 & 30.5 & 33.3 \\
\hline \multicolumn{4}{|c|}{ Cephalic perimeter $(\mathrm{cm})$} \\
\hline$<33$ & 11.6 & 5.8 & 5.8 \\
\hline$\geq 33$ & 88.4 & 44.2 & 44.2 \\
\hline \multicolumn{4}{|l|}{ Gender } \\
\hline Male & 56.4 & 29.1 & 27.3 \\
\hline Female & 43.6 & 20.9 & 22.7 \\
\hline
\end{tabular}

a Sample randomization criteria.

The dependent variables scored by a trained and reliable examiner. Inter-observer reliability was adequate considering Pearson Correlations between the two judges for continuous variables - seconds looking to the mother $(r=.90)$ and seconds looking to the stranger $(r=.81)$ - and Cohen's Kappa for the number of trials to reach habituation $(\kappa=.58)$ (Figueiredo et al., 2010).

\subsection{Procedures}

The research was approved by the Institution's Ethics Committee. The aims and procedures of the study were explained to participants and they all signed an informed consent form. Pregnant women were interviewed to collect socio-demographic data and filled out the EPDS at the third pregnancy trimester (between 28 and 37 weeks of gestation, $M=32.06, S D=3.34$ ) and at birth ( $1-5$ days after birth, $M=2.66, S D=1.67$ ).

On the first 5 days after birth the Neonatal Behavioral Assessment Scale (NBAS, Brazelton \& Nugent, 1995) followed by the "Preference and habituation to the mother's face/voice vs stranger" paradigm (Hernandez-Reif et al., 2002) were performed.

The "Preference and habituation to the mother face/voice versus stranger" paradigm included the mother, the newborn and two female experimenters (strangers to the newborn) that were used as strange figures. Along with the length of her hospital bed, the mother was placed between the two strangers. All 3 placed their feet on the floor and wore a white coat to minimize the presence of parasite variables and resorted to a black card $40 \mathrm{~cm} \times 22 \mathrm{~cm}$ to cover their face whenever they were not calling the newborn. Strangers and mothers were matched by hair color, skin tone and did not wear jewelry. The side of the strangers was counterbalanced. A third experimenter also wearing a white coat, hold the newborn at the same 
Table 2

Neonate behavioral assessment: differences between infants of depressed and non-depressed pregnant women.

\begin{tabular}{|c|c|c|c|c|c|c|}
\hline & Total, $M(S D)$ & Depressed, $M(S D)$ & Non-depressed, $M(S D)$ & Univariate $F$ & $\eta^{2}$ & $p$ \\
\hline Habituation & $5.13(3.49)$ & $4.51(3.60)$ & $5.75(3.30)$ & 3.509 & .031 & .064 \\
\hline Orientation & $5.28(2.04)$ & $5.55(1.84)$ & $5.01(2.20)$ & 1.947 & .018 & .166 \\
\hline Motor & $5.46(0.67)$ & $5.38(0.71)$ & $5.53(0.62)$ & 1.428 & .013 & .235 \\
\hline Range of state & $4.01(0.67)$ & $3.90(0.76)$ & $4.13(0.55)$ & 3.516 & .032 & .063 \\
\hline Regulation of state & $5.68(1.24)$ & $5.43(1.23)$ & $5.94(1.21)$ & 4.876 & .043 & .029 \\
\hline Autonomic stability & $6.38(0.98)$ & $6.23(1.08)$ & $6.54(0.86)$ & 2.762 & .025 & .099 \\
\hline Excitability score & $1.21(1.23)$ & $1.42(1.36)$ & $1.00(1.07)$ & 3.218 & .029 & .076 \\
\hline Depressed score & $2.13(2.51)$ & $1.73(2.13)$ & $2.53(2.80)$ & 2.843 & .026 & .095 \\
\hline NBAS total score ${ }^{\mathrm{a}}$ & $35.29(4.36)$ & $34.15(4.22)$ & $36.43(4.23)$ & 2.839 & - & .005 \\
\hline
\end{tabular}

Note: d.f. range $=(1,108)$.

Number of cases $=110$ : depressed $(n=55)$, non-depressed $(n=55)$.

a NBAS total score: independent samples $t$-test.

distance $(15-20 \mathrm{~cm})$ from the mother and the stranger who was calling it. At the beginning of each trial, the mother or the stranger was asked to lower her screen and to call the newborn, catching its attention by saying "hello baby", "look at me baby", making it look at her as long as possible (Figueiredo et al., 2010).

The NBAS was conducted by a trained and reliable examiner midway between feedings in a quiet and semi-darkened room with a temperature of $22-27^{\circ} \mathrm{C}$ and scored immediately after performed.

Newborn's age (hours of life) did not differ in infants from the depressed and non-depressed $(t(98)=-1.079, p=.283)$ mothers group.

\section{Results}

\subsection{Neonate behavioral assessment: differences between infants of depressed and non-depressed pregnant women}

A MANOVA followed by a univariate $F$ test was performed to identify potential differences in neonate behavioral assessment scores (NBASs: habituation, orientation, motor, range of state, regulation of state, autonomic stability, excitability, and depression) of depressed and non-depressed pregnant women after validation of the assumptions. The validation of the assumption of homogeneity of variances-covariances using the M-Box test was guaranteed $(M=44,848$; $F(3,639,247)=1.148 ; p=.249)$. Antenatal depression significantly affects neonate performance on the NBAS $(\Lambda=.167$; $F(8,101)=2.538 ; p=.015 ; \eta^{2}=.167 ;$ power $\left.=.895\right)$. Univariate analyses revealed that neonates of depressed pregnant women had a lower capacity of regulation of state. A marginal difference was also observed on habituation and range of state, with infants of depressed pregnant women performing worse in both scales. An independent $t$ test was performed to analyze differences in the NBAS total scale in newborns of depressed versus non-depressed pregnant women and revealed that neonates of depressed pregnant women had a lower total NBAS score (see Table 2).

\subsection{Neonate's visual/auditory preference and habituation to the mother and the stranger's face/voice: differences between infants of depressed and non-depressed pregnant women}

Non-parametric tests were performed because the data did not had a normal distribution for the groups under study. Mann-Whitney tests for independent samples were conducted for examining differences between the amount of time newborns looked at the mother versus the stranger in the visual/auditory preference pretest and in the visual/auditory preference posttest, in depressed (EPDS $\geq 10$ ) and non-depressed (EPDS $<10$ ) groups of pregnant women. The same analysis was also applied to the study of differences between depressed versus non-depressed groups regarding the amount of time newborns looked at the mother in the pretest visual/auditory preference, the mother in the posttest visual/auditory preference, the stranger in the pretest visual/auditory preference and the stranger in the posttest visual/auditory preference.

\subsubsection{Pretest visual/auditory preference}

Newborns of depressed pregnant women, compared with newborns of non-depressed pregnant women, spend significantly less time looking at their mothers $(Z=-3.493, p=.000)$; but no significant differences were observed in the duration of time that they spent looking at a stranger $(Z=-0.204, p=.420)$. In addition, newborns of depressed pregnant women did not attend longer to their mother's face/voice versus that of the stranger's $(Z=0.484, p=.316)$. Conversely, newborns of the nondepressed pregnant women group, looked significantly longer at their mother than at the stranger $(Z=-4.846, p=.000)$. Consequently, infants of non-depressed pregnant women present higher visual/auditory preference for their mothers' face/voice than do infants of the depressed pregnant women group $(Z=-3.653, p=.000)$ (see Table 3 ).

\subsubsection{Habituation}

Pearson's chi-square test revealed a significant association between infant habituation response to their mother's face/voice and the depressed versus non-depressed pregnant women groups $\left(\chi^{2}(2)=4,423, p=.028\right)$ : usually, infants of 
Table 3

Looking at the mother and at the stranger's face/voice at the visual/auditory preference pretest and posttest: differences between infants of depressed and non-depressed pregnant women.

\begin{tabular}{|c|c|c|c|}
\hline & Total $M(S D)$ & Depressed $M(S D)$ & Non-depressed $M(S D)$ \\
\hline \multicolumn{4}{|l|}{ Pretest } \\
\hline Mother & $9.59(7.62)$ & $7.75(6.28)$ & $11.43(8.42)$ \\
\hline Stranger & $6.72(5.58)$ & $7.15(6.37)$ & $6.28(4.69)$ \\
\hline Preference for the mother & $2.87(7.48)$ & $0.59(5.55)$ & $5.15(8.46)$ \\
\hline \multicolumn{4}{|l|}{ Posttest } \\
\hline Mother & $5.79(5.07)$ & $4.38(2.95)$ & $7.20(6.26)$ \\
\hline Stranger & $7.33(6.36)$ & $7.47(6.02)$ & $7.18(6.73)$ \\
\hline Preference for the stranger & $1.53(7.87)$ & $3.09(5.99)$ & $-0.02(9.18)$ \\
\hline
\end{tabular}

Measure unit: seconds of looking.

the depressed pregnant women group need 5-9 trials to achieve habituation ( $n=31,56.4 \%$ ), and only $21.8 \%$ ( $n=24)$ get habituation on the first 4 trials; infants of the non-depressed pregnant women group were commonly habituated in fewer trials ( 4 or less) $(n=35,63.6 \%)$, but $18.2 \%(n=20)$ needed 5-9 trials until the habituation response was observed.

\subsubsection{Posttest visual/auditory preference}

Newborns of depressed pregnant women, compared with newborns of non-depressed pregnant women, spend significantly less time looking at their mothers $(Z=-2.407, p=.008)$; and no significant differences were observed for the duration of the period that they looked at the stranger $(Z=-0.742, p=.230)$. Newborns of depressed pregnant women attended longer to the stranger's face/voice versus their mother's face/voice $(Z=-2.762, p=.003)$. Conversely, newborns of the non-depressed pregnant women group, did not look significantly longer at the stranger than at their mother $(Z=-0.394, p=.348)$. Consequently, infants of depressed pregnant women present a higher visual/auditory preference for the stranger's face/voice than do infants of non-depressed pregnant women $(Z=-2.255, p=.012)$ (see Table 2 ).

\subsubsection{Pretest visual/auditory preference and posttest visual/auditory preference}

Wilcoxon signed-rank tests were used for related samples to test for differences in the period for which the infants of depressed and non-depressed pregnant women looked at their mother and the stranger in the visual/auditory preference pretest versus posttest.

Newborns of depressed pregnant women looked significantly less at their mother in the posttest visual/auditory preference than in the pretest visual/auditory preference $(T=-3.942, p=.000)$. However, they did not look significantly longer at the stranger in the visual/auditory preference posttest than in the pretest visual/auditory preference $(T=-0.598, p=.277)$. The visual/auditory preference for the mothers' face/voice in the pretest was significantly lower than the preference for the strangers' face/voice in the posttest $(T=-2.000, p=.023)$.

Infants of mothers who were not depressed during pregnancy looked longer at their mothers in the pretest visual/auditory preference than in posttest visual/auditory preference $(T=-3.973, p=.000)$; they did not look longer at the stranger in the posttest visual/auditory preference than in the pretest visual/auditory preference $(T=-0.319, p=.077)$. The visual/auditory preference for the mother's face/voice in the pretest was significantly higher than the preference for the strangers' face/voice in the posttest $(T=-2.688, p=.003)$.

\subsection{Mother's depression at birth: mediation effects}

Four mediation models were tested to determine the effect of antenatal depression (dichotomous variable: $0=$ nondepressed, 1 =depressed) on neonatal: (1) behavioral assessment (NBAS total score - continuous variable); (2) pretest visual/auditory preference for the mother's face/voice (continuous variable), (3) habituation to the mother's face/voice (dichotomous variable: 0 = worse, 1 = better performance on habituation), and (4) posttest visual/auditory preference for the mother's face/voice (continuous variable). As a potential mediator, we considered the mother's depression at birth (dichotomous variable: $0=$ non-depressed, 1 =depressed). There were no problems of multicollinearity between variances of the variables considered on the regression analyses attending the Variance Inflation Factor of $<5$ and the Tolerance $>0.2$ (Field, 2005).

Several linear/logistic regression analyses were performed (Baron \& Kenny, 1986; Judd \& Kenny, 1981) in each of the 4 mediation models tested. In the first equation, the mother's antenatal depression was entered as the independent variable and the neonate behavioral assessment score as the criterion in model 1, the pretest visual/auditory preference for the mother's face/voice as the criterion in model 2, habituation to the mother's face/voice as the criterion in model 3, and posttest visual/auditory preference for the stranger's face/voice as the criterion in model 4.

Results revealed that depression in pregnant women predicts: the neonate behavioral assessment - the model was statistically significant and explained $6.1 \%$ of the variance observed $\left(F(1,108)=8.060 ; p=.005 ; R^{2}{ }_{\mathrm{a}}=.061\right)$; pretest visual/auditory preference for the mother's face/voice - the model was statistically significant and explained $8.5 \%$ of the variance observed $\left(F(1,108)=11.132 ; p=.001 ; R^{2}{ }_{\mathrm{a}}=.085\right)$; habituation to the mother's face/voice - the model was statistically significant and 
Table 4

Mediation and moderation models tests: linear regression analyses.

\begin{tabular}{|c|c|c|c|c|c|c|}
\hline & $R^{2}\left(R_{\mathrm{a}}^{2}\right)$ & $F$ & $p$ & $\beta$ & $t$ & $p$ \\
\hline Neonate behavioral assessment: antenatal depression & $.069(.061)$ & 8.060 & .005 & -.264 & -2.839 & .005 \\
\hline Pretest preference: antenatal depression & $.093(.085)$ & 11.132 & .001 & -.306 & -3.336 & .001 \\
\hline Posttest preference: antenatal depression & $.039(.030)$ & 4.423 & .038 & .198 & 2.1038 & .038 \\
\hline Neonate behavioral assessment: depression at birth & $.173(.030)$ & 3.313 & .072 & -.173 & -1.820 & .072 \\
\hline Pretest preference: depression at birth & $.005(-.004)$ & 0.525 & .470 & -.070 & -0.725 & .470 \\
\hline Posttest preference: depression at birth & $.000(-.009)$ & 0.030 & .864 & .017 & 0.172 & .864 \\
\hline
\end{tabular}

Table 5

Mediation and moderation models tests: logistic regression analyses.

\begin{tabular}{lllrrrr}
\hline & $B$ & $S E$ & $\chi^{2}$ wald & d.f. & $p$ & Exp $(B)$ \\
\hline Depression at birth: antenatal depression & 2.282 & .510 & 20.004 & 1 & .000 & 9.800 \\
Habituation: antenatal depression & 0.816 & .391 & 4.362 & 1 & .037 & 0.442 \\
Habituation: depression at birth & 0.146 & .191 & 0.581 & 1 & .446 & 1.157 \\
\hline
\end{tabular}

correctly classified $60 \%$ of the cases $\left(G^{2}(1)=4.454, p=.035, R^{2}{ }_{C S}=.040, R^{2}{ }_{N}=.053\right)$; and posttest visual/auditory preference for the stranger's face/voice - the model was statistically significant and explained $3 \%$ of the variance observed $(F(1,108)=4.423$; $\left.p=.038 ; R^{2}{ }_{a}=.030\right)$ (see Tables 4 and 5 ).

In the second equation (common to the 4 mediation models), depression during pregnancy was entered as the independent variable and mother's depression at birth as the criterion. Antenatal depression predicted the mother's depression at birth; the models were statistically significant and correctly classified 71.8\% of the cases $\left(G^{2}(1)=25.393, p=.000, R^{2}\right.$ CS $=.206$, $R^{2}{ }_{\mathrm{N}}=.287$ ) (see Tables 4 and 5 ).

In the third equation, mother's depression at birth was entered as the independent variable and the neonate behavioral assessment as the criterion in model 1; pretest visual/auditory preference for the mother's face/voice as the criterion in model 2; habituation to the mother's face/voice as the criterion in model 3; and the posttest visual/auditory preference for the stranger's face/voice as the criterion in model 4. Mother's depression at birth did not predict the: neonate behavioral assessment $\left(F(1,108)=3.313 ; p=.072 ; R_{a}^{2}=.021\right)$; pretest visual/auditory preference for the mother's face $/$ voice $[(F(1,108)=.525$; $\left.\left.p=.470 ; R_{\mathrm{a}}=-.004\right)\right]$; habituation to the mother's face/voice $\left(G^{2}(1)=.016, p=.900, R^{2}{ }_{\mathrm{CS}}=.000, R^{2}{ }_{\mathrm{N}}=.000\right)$; or the posttest visual/auditory preference for the stranger's face/voice $\left[\left(F(1,108)=.030 ; p=.864 ; R^{2}{ }_{\mathrm{a}}=-.009\right)\right]$, and was consequently not a mediator in the models (see Tables 4 and 5).

\subsection{Mother's depression at birth: moderation effects}

To test whether the mother's depression at birth influences the effect of antenatal depression on neonate behavioral development (considering the neonate behavioral assessment, pretest visual/auditory preference for the mother's face/voice, habituation to the mother's face/voice and the posttest visual/auditory preference for the stranger's face/voice) (moderator effect), 3 conditions are required (Baron \& Kenny, 1986): (1) the effect of women's antenatal depression on neonate behavioral development, (2) the effect of mother's depression at birth on neonate behavioral development, and (3) the effect of the interaction between women's antenatal depression and the mother's depression at birth on neonate behavioral development. Previous analyses showed that the variations in mother's depression at birth do not account for variations in neonate behavioral development in any of the dimensions assessed in this study: neonate behavioral assessment, pretest visual/auditory preference for the mother's face/voice, habituation to the mother's face/voice, or posttest visual/auditory preference for the stranger's face/voice (see Tables 4 and 5). Consequently, no moderation effects were identified.

\section{Discussion}

This work addressed questions regarding the impact of depression in mothers on neonatal development. In particular, we studied the effect of third-trimester depression on neonate behavior, preference and habituation to the face/voice of the mother and of a stranger. Mediation and moderation models tested whether a mother's depressive symptomatology at birth is a potential mediator/moderator of the relationship between the mother's antenatal depression and neonate behavioral development.

Our results revealed that 1-to-5-day-old newborns whose mothers were depressed antenatally performed poorly on the NBAS scale compared to newborns of non-depressed pregnant women: they had lower total score; decreased capacity in the regulation of state, range of state (marginal difference), and habituation (marginal difference). Previous studies have also found an association between antenatal depression and neonatal performance on the NBAS. Newborns of women with depressive symptoms had lower scores on habituation, orientation, motor, range of state, autonomic stability and depression (Field et al., 2004); showed more irritability; and less activity, robustness endurance (Abrams et al., 1995), alertness, cuddliness, and hand-to-mouth behaviors during the assessment (Hernandez-Reif et al., 2006). 
In terms of neonate's visual/auditory preference for the mother versus a stranger's face/voice, our results indicate that neonates of non-depressed mothers look longer at their mothers than at a stranger, showing a preference for the mother's versus a stranger's face/voice. These results are similar to those of other authors (e.g. Field et al., 1984; Figueiredo et al., 2010; Hernandez-Reif et al., 2002). Contrarily, neonates of depressed mothers look at their mothers for shorter periods, showing no visual/auditory preference for the mother's face/voice; this corroborates the results of other studies in which it is suggested the absence of this important perceptual and social competence in newborns of mothers depressed antenatally (Figueiredo et al., 2010) and after childbirth (Hernandez-Reif et al., 2002).

Subsequently, after repeated presentation of the mother's face/voice, a decrease in neonate attention was observed. This habituation response to the mother's face/voice, which is also described by other authors (e.g. Field et al., 1984; Figueiredo et al., 2010; Hernandez-Reif et al., 2002), did not require more than 4 trials in the majority of the neonates of non-depressed mothers. On the contrary, neonates of depressed mothers frequently needed more trials (5-9) until habituation occurred. Similarly, Hernandez-Reif et al. (2002) found that infants of depressed mothers required more trials and almost twice as long as the infants of non-depressed mothers to habituate to their mother's face/voice. These results could indicate lowered cognitive development since a longer time to habituation has been correlated with cognitive deficits later in life, including low IQ (Laucht, Esser, \& Schmidt, 1994; McCall, 1994). In relation to the variable - number of trials to reach habituation - a lower Cohen's Kappa $(\kappa=.58)$ (Figueiredo et al., 2010) was obtained, suggesting disagreements between coders, which should be considered a study limitation.

In accordance with the literature (Field et al., 1984; Figueiredo et al., 2010; Hernandez-Reif et al., 2002), we found that after habituation to the mother's face/voice, the newborn's preference for a stranger's face/voice was observed, indicating the newborn capacity for recognizing the characteristics of their mother's face/voice, detecting differences between 2 female faces/voices, and exploring new information when provided Neonates of depressed mothers looked longer at strangers than at their mother's face or listen to her voice, showing a higher visual/auditory preference for the stranger's face/voice compared with neonates of non-depressed mothers. This result, in association with the fact that in a pretest visual/auditory preference, neonates of depressed mothers spend significantly less time looking at their mothers, may result from both the lowered capacity of the mother to call and keep the infant's attention to her and the lower capacity of the neonate to recognize the mother. This might be a consequence of fewer learning experiences provided by their mothers during gestation (DiPietro, 2005; Lecanuet \& Jacquet, 2002). On the contrary, neonates of non-depressed pregnant women spend more time looking at their mothers and do not attend significantly more often at the stranger's versus the mother's face/voice in the posttest. This seems a contradictory result, because it associates neonates of non-depressed pregnant women with a lower capacity for processing new information (Sokolov, 1963; Kavsek \& Bornstein, 2010). Nonetheless, it may be explained by the importance of establishing a unique care relationship with the mother to assure infant survival. From birth, neonates have specific responses to human stimuli that result both from genetic selection and from learning experiences during gestation; this guarantees a social pre-adaptation that enhances newborn survival. The mother, as the attachment figure, will be the preferential object of neonate attention (Bowlby, 1969). Moreover, the lower agreement between coders on the habituation score could report a false habituation response to the mother's face/voice stimulus; consequently, the infants were still processing the maternal information when they were assessed for the novelty preference response.

When the pretest visual/auditory preference is compared with the posttest visual/auditory preference, all the neonates were generally found to look at their mothers for shorter periods, showing that habituation to the mother's face/voice occurred (e.g. Clifton \& Meyers, 1969; Graham, Clifton, \& Hatton, 1968), but no significant differences were observed in relation to the stranger's face or voice. A difference between neonates of depressed and non-depressed pregnant women exists in the preference for the mother's face/voice in pretest, and the preference for the stranger's face/voice in posttest: neonates of depressed pregnant women have a significantly lower visual/auditory preference for their mothers in pretest than for strangers in posttest; neonates of non-depressed pregnant women have a significantly higher visual/auditory preference for mothers in pretest than for strangers in posttest. These results may also indicate that neonates of non-depressed pregnant women have good survival instincts and are investing in the relationship with their mothers. On the contrary, neonates of depressed mothers are more focused upon the processing of new stimuli, this might be due to a compromised maternal capacity to keep the neonate's attention (Murray, Kempton, Woolgar, \& Hooper, 1993), in contrast to the non-depressed mothers group.

With regard to our second aim, it was expected that the mother's depression at birth would mediate/moderate the relationship between women's antenatal depression and neonatal behavioral development. A mediation model seeks to identify and explain the mechanisms that underlie an observed relationship between an independent variable and a dependent variable via the inclusion of a third explanatory variable. A moderation model investigates whether the relationship between 2 variables depends on a third variable (the moderator). The effect of a moderating variable is statistically characterized as an interaction that affects the direction and/or strength of the relationship between dependent and independent variables (Holmbeck, 2002; Rose, Holmbeck, Coakley, \& Franks, 2004).

We hypothesized that the effects of the mother's antenatal depression on neonate behavioral development was a result of the mother being depressed at the time of birth; this was not confirmed by the data. In fact, results pointed to the possibility that antenatal depression may be the origin of behavioral difficulties in neonates and does not depend on the mother's depression shortly after birth (Davis et al., 2007; Field et al., 2006; O'Connor et al., 2007), but rather on the greater adverse impact that antenatal depression may have on fetal development. A possible underlying mechanism is the excess of circulating maternal stress hormones, such as cortisol and corticotrophin-releasing hormone, as already described in 
depressed pregnant women (Field, 1998; Gitau, Cameron, Fisk, \& Glover, 1998) and, consequently, in their fetus. This alters the programming of fetal neurons and its effects seem to persist after childbirth (Weinstock, 2010).

A previous study (Figueiredo et al., 2010) found that depression during pregnancy, and not at birth, explains the newborn's preference for the mother's face/voice. Data seems to reinforce the adaptive function of the mother's depressive mood at birth but does not claim the impact of chronic maternal depression (depression that persists in the peripartum period) on infant development. Similarly, Campbell, Cohn, and Meyers (1995) found that postnatal depression that lasted into the infant's sixth month, but not depression in the first 2 months after birth, predicted the quality of the mother-infant interaction. Field (1992) reported that 1-year-old infants of mothers who had been depressed early in the postpartum period but not at 6 months postpartum did not display a 'depressed' style of interaction or showed impaired motor or mental development.

The results of this study lead us to conclude that women's depressive symptoms are an important issue, relevant for consideration in routine health care throughout pregnancy and not only after birth. The behavioral development of infants of depressed mothers is already compromised at birth (Abrams et al., 1995; Lundy et al., 1996). This highlights the importance of implementing interventions as early as possible, in particular, through therapeutic interventions that focus on the mother-infant dyad and the infant's affective state. These could produce positive effects on infant development and also for the mother's recovery from depression. In addition, considering the impact of antenatal depression on the development of perceptive and cognitive competencies, the identification of fetal indicators of risk should be our next research challenge in comprehension of the relationship between depression in pregnant women and neonate behavioral development.

\section{Acknowledgments}

The study was financed by “FCT - Fundação para a Ciência e Tecnologia” (Grant SFRH/BD/21956/2005), Ministry of Science, Technology and Higher Education in the scope of POCI 2010. Advanced training for science - measure IV.3. Reimbursed by the European Social Fund - Operational Human Potential Program (POPH) - and by National Funds of MCTES.

\section{References}

Abrams, S. M., Field, T., Scafidi, F., \& Prodromidis, M. (1995). Newborns of depressed mothers. Infant Mental Health Journal: $16 ., 233-239$.

Andersson, L., Sundstrom-Poromaa, I., Wulff, M., Astrom, M., \& Bixo, M. (2004). Neonatal Outcome following maternal antenatal depression and anxiety: A population-based study. Journal of Epidemiology: 159., 872-881.

Areias, M. E. G., Kumar, R., Barros, H., \& Figueiredo, E. (1996). Correlates of postnatal depression in mothers and fathers. British Journal of Psychiatry: 169., 36-41.

Baron, R. M., \& Kenny, D. A. (1986). The moderator-mediator variable distinction in social psychological research: Conceptual, strategic and statistical considerations. Journal of Personality and Social Psychology: 51., 1173-1182.

Bowlby, J. (1969). Attachment and Loss : Vol. 1. New York: Basic Books.

Brazelton, T. B., \& Nugent, J. K. (1995). Neonatal behavioral assessment scale (3rd ed.). London: Mac Keith Press.

Campbell, S. B., Cohn, J., \& Meyers, T. (1995). Depression in first-time mothers: Mother-infant interaction and depression chronicity. Developmental Psychology: 31., 349-357.

Clifton, R. K., \& Meyers, W. J. (1969). The heart-rate response of four-month-old infants' perception of possible and impossible events. Infancy: 1., 429-446.

Costa, R., Figueiredo, B., Tendais, I., Conde, A., Pacheco, A., \& Teixeira, C. (2010). Brazelton neonatal behavioral assessment scale: A psychometric study in a Portuguese sample. Infant Behavior and Development: 33., (4), 510-517.

Costa, R., Pacheco, A., \& Figueiredo, B. (2007). Prevalência e preditores de sintomatologia depressiva após o parto. Revista de Psiquiatria Clínica: 34., (4), 157-165.

Cox, J. L., Holden, J. M., \& Sagovsky, R. (1987). Detection of postnatal depression: Development of the 10-item Edinburgh Postnatal Depression Scale. British Journal of Psychiatry: 150., 782-786.

Da Costa, D., Larouche, J., Dritsa, M., \& Brender, W. (2000). Psychosocial correlates of prepartum and postpartum depressed mood. Journal of Affective Disorders: 59., (1), 31-40.

Davis, E. P., Glynn, L. M., Schetter, C. D., Hobel, C., Chicz-Demet, A., \& Sandman, C. A. (2007). Prenatal exposure to maternal depression and cortisol influences infant temperament. Journal of the American Academy of Child and Adolescent Psychiatry: 46., (6), 737-746.

Dayan, J., Creveuil, C., Marks, M. N., Conroy, S., Herlicoviez, M., Dreyfus, M., et al. (2006). Prenatal depression, prenatal anxiety and spontaneous preterm birth: A prospective cohort study among women with early and regular care. Psychosomatic medicine: 68., 938-946.

Dieter, J., Emory, E., Johnson, K., \& Raynor, B. (2008). Maternal depression and anxiety effects on the human fetus: Preliminary findings and clinical implications. Infant Mental Health Journal: 29., (5), 420-441.

Diego, M. A., Field, T., \& Hernandez-Reif, M. (2005). Prepartum, postpartum, and chronic depression effects on neonatal behavior. Infant Behavior and Development: 28., (2), 155-164.

DiPietro, J. A. (2005). Neurobehavioral assessment before birth. Mental Retardation and Developmental Disabilities Research Reviews: 11., (1), 4-13.

Felice, E., Saliba, J., Grech, V., \& Cox, J. (2004). Prevalence rates and psychosocial characteristics associated with depression in pregnancy and postpartum in Maltese women. Journal of Affective Disorders: 82., (2), 297-301.

Field, A. (2005). Discovering statistics using SPSS. London: SAGE Publications.

Field, T. (1992). Infants of depressed mothers. Developmental Psychopathology: 4., 49-66.

Field, T. (1998). Maternal depression effects on infants and early interventions. Preventive Medicine: 27., 200-203.

Field, T. M., Cohen, D., Garcia, R., \& Greenberg, R. (1984). Mother-stranger face discrimination by the newborn. Infant Behavior and Development: 7., (1), $19-25$.

Field, T., Diego, M., Dieter, J., Hernandez-Reif, M., Schanberg, S., Kuhn, C., et al. (2004). Prenatal depression effects on the fetus and the newborn. Infant Behavior and Development: 27., 216-229.

Field, T., Hernandez-Reif, M., Diego, M., Figueiredo, B., Schanberg, S., \& Kuhn, C. (2006). Prenatal cortisol prematurity and low birthweight. Infant Behavior and Development: 29., 268-275.

Figueiredo, B., Pacheco, A., Costa, R., \& Magarinho, R. (2007). Depression during pregnancy and the postpartum period in adolescent and adult Portuguese mothers. Archives of Women's Mental Health: 10., (3), 103-109.

Figueiredo, B., Pacheco, A., Costa, R., Conde, A., \& Teixeira, C. (2010). Mother's anxiety and depression during the third pregnancy trimester and neonate's mother versus stranger's face/voice visual preference. Early Human Development: 86., (8), 479-485.

Gitau, R., Cameron, A., Fisk, N. M., \& Glover, V. (1998). Fetal exposure to maternal cortisol. Lancet: 352., 707-708. 
Gorman, L., O'Hara, M., Figueiredo, B., Hayes, S., Jaquemain, F., Klier, C., et al. (2004). Adaptation of the structured clinical interview for DSM-IV disorder for assessing depression in women during pregnancy and postpartum across countries and cultures. British Journal of Psychiatry: $184 .$, (Suppl. 46 ), 18-25.

Glover, V. (1997). Maternal stress or anxiety in pregnancy and emotional development of the child. British Journal of Psychiatry: 171., (8), 105-106.

Graham, F. K., Clifton, R. K., \& Hatton, H. M. (1968). Habituation of heart-rate response to repeated auditory stimulation during the first five days of life. Child Development: 39., 35-52.

Hannah, P., Adams, D., Lee, A., Glover, V., \& Sandler, M. (1992). Links between early post-partum mood and post-natal depression. British Journal of Psychiatry: 160., 777-780.

Hernandez-Reif, M., Field, T., Diego, M., \& Largie, S. (2002). Depressed mothers' newborns show longer habituation and fail to show face/voice preference. Infant Mental Health Journal: 23., (6), 643-653.

Hernandez-Reif, M., Field, T., Diego, M., \& Ruddock, M. (2006). Greater arousal and less attentiveness to face/voice stimuli by neonates of depressed mothers on the Brazelton Neonatal Behavioral Assessment Scale. Infant Behavior E Development: 29., (4), 594-598.

Holmbeck, G. N. (2002). Post hoc probing of significant moderational and mediational effects in studies of pediatric populations. Journal of Pediatric Psychology: 27., (1), 87-96.

Judd, C. M., \& Kenny, D. A. (1981). Process analysis: Estimating mediation in treatment evaluations. Evaluation Review: 5., (5), $602-619$.

Kavsek, M., \& Bornstein, M. H. (2010). Visual habituation and dishabituation in preterm infants: A review and meta-analysis. Research in Developmental Disabilities: 31., (5), 951-975.

Kitamura, T., Yoshida, K., Okano, T., Kinoshita, K., Hayashi, M., Toyoda, N., et al. (2006). Multicentre prospective study of perinatal depression in Japan: Incidence and correlates of antenatal and postnatal depression. Archives of Women's Mental Health: 9., (3), 121-130.

Klaus, M., \& Kennell, J. (1976). Maternal-infant bonding. Saint Louis: The C. V. Mosby Company.

Kraemer, H. C., Stice, E., Kazdin, A., Offord, D., \& Kupfer, D. J. (2001). How do risk factors work together? Mediators, moderators, and independent, overlapping, and proxy risk factors. American Journal of Psychiatry: 158., 848-856.

Laucht, M., Esser, G., \& Schmidt, M. H. (1994). Contrasting infant predictors of later cognitive functioning. Journal of Child Psychology and Psychiatry, and allied disciplines: 35., (4), 649-662.

Lecanuet, J. P., \& Jacquet, A. Y. (2002). Fetal responsiveness to maternal passive swinging in low heart rate variability state: Effects of stimulation direction and duration. Developmental Psychobiology: 40., (1), 57-67.

Lovejoy, M. C., Graczyk, P. A., O’Hare, E., \& Neuman, G. (2000). Maternal depression and parenting behavior: A meta-analytic review. Clinical Psychology Review: 20., (5), 561-592.

Lundy, B. L., Field, T., \& Pickens, J. (1996). Newborns of depressed mothers are less expressive. Infant Behavior and Development: 19., 421-426.

Lundy, B. L., Jones, N. A., Field, T., Nearing, G., Davalos, M., Pietro, P., et al. (1999). Prenatal depression effects on neonates. Infant Behavior and Development: 22., 121-131.

Marcus, S. M., Flynn, H. A., Blow, F. C., \& Barry, K. L. (2003). Depressive symptoms among pregnant women screened in obstetrics settings. Journal of Women's Health: 12., 373-380.

Marcus, S., Lopez, J. F., McDonough, S., Mackenzie, M. J., Flynn, H. N., et al. (2011). Depressive symptoms during pregnancy: Impact on neuroendocrine and neonatal outcomes. Infant Behavior and Development: 34., (1), 26-34.

McCall, R. (1994). What process mediates predictions of childhood IQ from infant habituation and recognition memory? Speculations on the roles of inhibition and rate of information processing. Intelligence: 18., 107-125.

Murray, L., Kempton, C., Woolgar, M., \& Hooper, R. (1993). Depressed mothers' speech to their infants and its relation to infant gender and cognitive development. Journal of Child Psychology and Psychiatry: 34., 1083-1101.

O'Donnell, K., O'Connor, T. G., \& Glover, V. (2009). Prenatal stress and neurodevelopment of the child: focus on the HPA axis and the role of the placenta. Developmental neuroscience: 31., (4), 285-292.

O'Hara, M. W., Zekoski, E. M., Philipps, L. H., \& Wright, E. J. (1990). Controlled prospective study of postpartum mood disorders: Comparison of childbearing and nonchildbearing women. Journal of Abnormal Psychology: 99., 3-15.

O'Connor, T. G., Caprariello, P., Blackmore, E., Gregory, A. M., Glover, V., Fleming, P., et al. (2007). Prenatal mood disturbance predicts sleep problems in infancy and toddlerhood. Early Human Development: 83., (7), 451-458.

Payne, J. L. (2003). The role of estrogen in mood disorders in women. International Review of Psychiatry: 15., $280-290$.

Romo, A., Carceller, R., \& Tobajas, J. (2009). Intrauterine growth retardation (IUGR): Epidemiology and etiology. Pediatric Endocrinology Reviews: 6., (Suppl. 3), 332-336.

Sohr-Preston, S. L., \& Scaramella, L. V. (2006). Implications of timing of maternal depressive symptoms for early cognitive and language development. Clinical Child and Family Psychology Review: 9., (1), 65-83.

Sokolov, E. N. (1963). Perception and the conditioned reflex. Hillsdale, NJ: LEA.

Rose, B. M., Holmbeck, G. N., Coakley, R. M., \& Franks, E. A. (2004). Mediator and moderator effects in developmental and behavioral pediatric research. Journal of Developmental and Behavioral Pediatrics: 25., (1), 58-67.

Teissedre, F., \& Chabrol, H. (2004). Detecting women at risk of postnatal depression using the EPDS at 2 to 3 days postpartum. Canadian Journal of Psychiatry: 49., 51-54.

Teixeira, C., Figueiredo, B., Conde, A., Pacheco, A., \& Costa, R. (2009). Anxiety and depression during pregnancy in women and men. Journal of Affective Disorders: 119., (1-3), 142-148.

Weinstock, M. (2010). Intrauterine factors as determinants of depressive disorder. The Israel Journal of Psychiatry and Related Sciences: 47., (1), 36-45. 